$\S=-1$

\title{
Effect of Utilizing Prosopis Juliflora Ash as Cementitious Material
}

\author{
George Amal Anik $\mathbf{S}^{1}$, Parthiban Kathirvel ${ }^{2 *}$, Murali $\mathbf{G}^{3}$ \\ School of Civil Engineering, SASTRA Deemed University, Thanjavur, India. \\ *Corresponding Author E-mail: ${ }^{2}$ parthiban@ civil.sastra.edu
}

\begin{abstract}
Since the building made of cement concrete consumes almost half of the total energy generated and accordingly accountable for huge amount of $\mathrm{CO}_{2}$ emission, it is necessary to replace the Portland cement (PC) with sustainable construction material. Similarly, Prosopis juliflora is a shrub or small tree in the family Fabaceae, a kind of mesquite which is considered to be a potential threat for ground water in South India. Hence, this has to eradicate so as to maintain the groundwater and also to effectively utilize its ash thereby reducing environmental pollution, this can be used as a partial replacement for cement. In this regard, this paper investigates the technical feasibility of using prosopis juliflora ash (PJA) as cementitious material by partially (10, 20,30 and $40 \%)$ replacing cement by prosopis juliflora ash. The mixes were evaluated for their fresh, physical and strength properties such as workability, density and compressive strength and the results were compared with the conventional mix
\end{abstract}

\section{Introduction}

Concrete is the most widely recognized material utilized as a part of construction industry. Cement is the major component of concrete used for building and civil engineering construction [1]. For each human being approximately 1 ton of concrete is produced each year in the world [2]. Therefore cement is one of the World's most significant manufactured materials. 5\% of the total release of $\mathrm{CO}_{2}$ to the atmosphere is caused during the manufacturing for cement in cement industries [3]. In an effort to reduce anthropogenic $\mathrm{CO}_{2}$ emission and for the economic reasons by-products are used as cementitious materials [4]. Utilization of non-regular and creative materials, and reusing of waste materials to repay the absence of common assets and to discover elective routes for moderating the earth [5]. Many industrial by-products and waste materials such as copper slag [6], fly ash [7], waste brick, bottom ash [8], timber waste [9], ground granulated blast slag [10] were used as replacement of cement. Prosopis juliflora is a bush or little tree in the family Fabaceae, a sort of mesquite. Prosopis juliflora, once touted as a saviour of the dry spell inclined. Prosopis was presented in India amid the 1870s to take care of the fuel wood demand. Prosopis juliflora is a invasive plants, which is the reason for negative biodiversity in many partsof the world. With intense infiltrating roots, it can draw water from very great layers. Its underlying foundations can develop to an incredible profundity looking for water. It sucks excessively of groundwater by profound entrance of their underlying foundations and furthermore makes the water toxic. No other plant or bush could become alongside it. Fresh properties of cement such as consistency and setting time, density, soundness were evaluated. Five different proportions for cement paste and mortar were prepared. Compressive strength on 3,7 and 28 days were evaluated.

\section{Materials and Methods}

\subsection{Materials}

\section{Cement}

OPC 43 grade cement with minimum compressive strength of 45 $\mathrm{MPa}$ and initial setting time of 32 minutes and specific gravity of 3.15 obtained from the local supplier was used in this investigation with the chemical composition detailed in Table 1.

\section{Prosopis Juliflora}

Prosopis Juliflora Ash (PJA) obtained from the nearest field with a specific gravity 3.00 , mean particle size $35 \mu \mathrm{m}$ was used as a partial replacement of cement in this investigation. The chemical composition of the ash is given in Table 1 .

Table 1: Chemical composition of the source materials used

\begin{tabular}{|l|l|l|l|l|l|l|l|}
\hline $\begin{array}{l}\text { Oxide } \\
(\%)\end{array}$ & $\mathbf{C a O}$ & $\mathbf{K}_{\mathbf{2}} \mathbf{O}$ & $\mathbf{S O}_{\mathbf{3}}$ & $\mathbf{M g O}$ & $\mathbf{S i O}_{\mathbf{2}}$ & $\mathbf{N a}_{\mathbf{2}} \mathbf{O}$ & $\mathbf{F e}_{2} \mathbf{O}_{\mathbf{3}}$ \\
\hline OPC & 63.12 & 0.63 & 1.43 & 2.16 & 24.52 & 0.44 & 3.51 \\
\hline PJA & 59.45 & 23.85 & 4.44 & 1.70 & 1.19 & 0.84 & 0.57 \\
\hline
\end{tabular}

Table 2: Mix Proportion Table for Cement Paste

\begin{tabular}{|l|l|l|l|}
\hline $\begin{array}{l}\text { Replacement of cement with } \\
\text { prosopis juliflora ash (\%) }\end{array}$ & $\begin{array}{l}\text { Cement } \\
\text { (g) }\end{array}$ & PJA (g) & $\begin{array}{l}\text { Water } \\
\text { (ml) }\end{array}$ \\
\hline M1 & 600 & 0 & 210 \\
\hline M2 & 540 & 60 & 210 \\
\hline M3 & 480 & 120 & 210 \\
\hline M4 & 420 & 180 & 215 \\
\hline M5 & 360 & 240 & 215 \\
\hline
\end{tabular}

Compressive strength of cement paste when cement replaced with various percentage of prosopis juliflora ash for 3, 7 and 28 days were tested. The results are summarized and shown in table 3 .

Table 3: Compressive Strength of Cement Paste

\begin{tabular}{|l|l|l|l}
\hline Replacement of cement with & 3 days & 7days & 28days \\
\hline
\end{tabular}




\begin{tabular}{|l|l|l|l|}
\hline prosopis juliflora ash (\%) & & & \\
\hline M1 & 28.18 & 35.25 & 51.25 \\
\hline M2 & 21.18 & 31.56 & 44.53 \\
\hline M3 & 19.51 & 22.34 & 35.81 \\
\hline M4 & 16.62 & 17.62 & 34.43 \\
\hline M5 & 15.12 & 16.51 & 27.25 \\
\hline
\end{tabular}

\section{Aggregates}

Locally available graded river sand was taken as fine aggregates with a nominal maximum size of $4.75 \mathrm{~mm}$ with a specific gravity of 2.6 and crushed granite as coarse aggregate with a maximum size of $16 \mathrm{~mm}$ with a specific gravity of 2.64 .

\subsection{Mix Design}

The mortar samples were prepared in the proportion of 1:3.The mixes were prepared confirming to Indian standards, IS 10262:2009. Five different mixes of cement paste and mortar with cement replacement of $0 \%, 10 \%, 20 \%, 30 \%$, and $40 \%$ were prepared. The mixes were placed in the cube moulds with a three layer compaction. The moulds were cured in water bath under room temperature condition for the designated testing period.

Table 4: Mix Proportion of Cement Mortar

\begin{tabular}{|l|l|l|l|l|}
\hline $\begin{array}{l}\text { Replacement of } \\
\text { OPC with PJA } \\
(\%)\end{array}$ & $\begin{array}{l}\text { Cement } \\
(\mathbf{g})\end{array}$ & $\begin{array}{l}\text { PJA } \\
(\mathbf{g})\end{array}$ & Sand (g) & Water (ml) \\
\hline 0 & 925 & 0 & 2775 & 453 \\
\hline 10 & 832.5 & 92.5 & 2775 & 453 \\
\hline 20 & 740 & 185 & 2775 & 453 \\
\hline 30 & 647.5 & 277.5 & 2775 & 485 \\
\hline 40 & 555 & 370 & 2775 & 485 \\
\hline
\end{tabular}

\subsection{Testing Methods}

Consistency and setting time of different mixes with $0 \%$ to $40 \%$ replacement of cement were carried out based on Indian standards
IS:4031:Part 4 and soundness test based on IS:4031:Part 3 were carried out. Based on IS: 4031: Part 10 shrinkage test were done on mould size of $76 \times 10 \times 10 \mathrm{~mm}$ size. Cube specimens of $40 \times 40$ x $40 \mathrm{~mm}$ size were used for compressive strength of cement paste. Specimens for mortar were placed in a cube of $70 \times 70 \times 70 \mathrm{~mm}$. The compressive strength test for both cement paste and mortar for 3, 7 and 28 days were carried out.

\section{Results and Discussion}

\section{Consistency and initial setting time}

The fresh properties such as consistency and setting time were analyzed and their results are detailed in figure 1.the results of consistency test shows that the optimum water content required for cement paste is $35 \%$ upto $20 \%$ of replacement of cement with prosopis juliflora ash. For $30 \%$ and $40 \%$ the optimum water content for the required consistency is increased to $37.5 \%$. This may be due to the hygroscopic character and increased surface area of prosopis juliflora ash which leads to increase the water demand. The setting time of cement paste increases with the increase in percentage of prosopis juliflora ash as replacement of cement. Initial setting time of cement paste at room temperature increases from 32 to $50 \mathrm{~min}$, when replaced by $40 \%$. This is mainly due to the water holding characteristics of prosopis juliflora ash and loss of tri-calcium aluminate from cement which delays the hydration process and increases duration of setting. Besides, prosopis juliflora ash isn't much responsive as cement, which may likewise prompts the expanded setting time of the mixes with the increasing volume of prosopis juliflora ash.

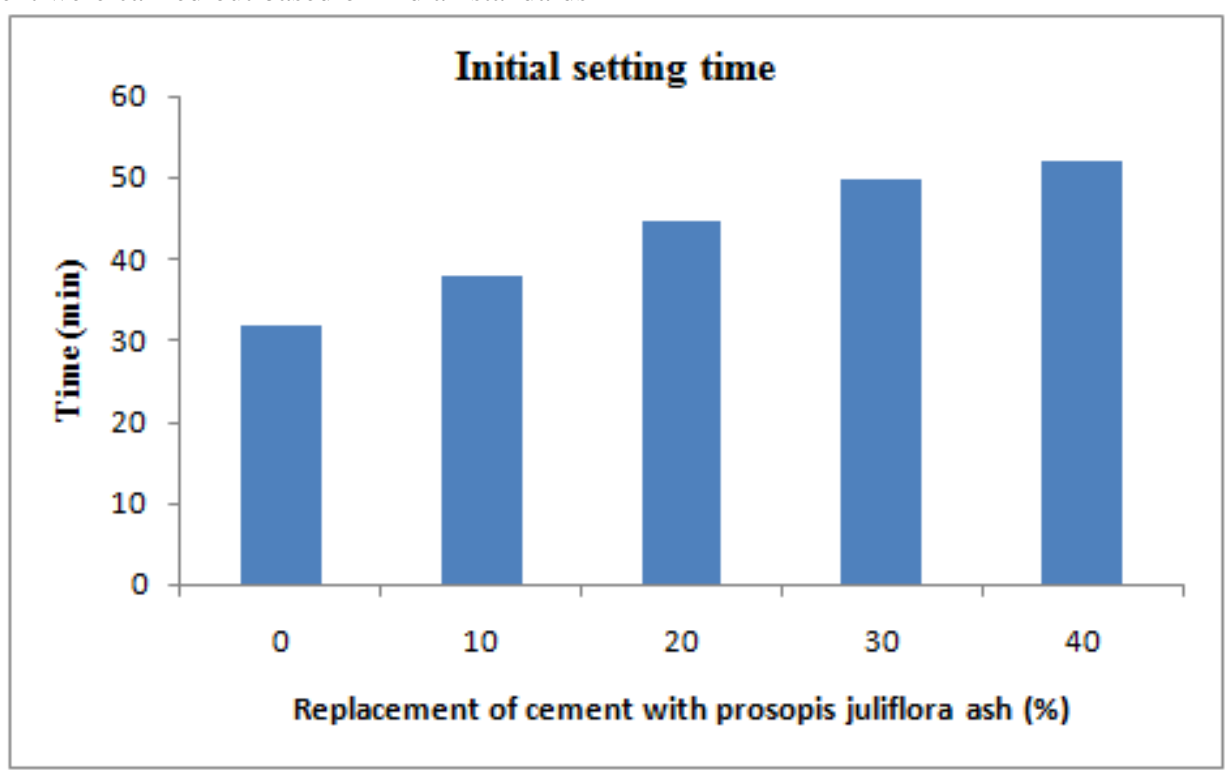

Fig. 1: Initial Setting Time

\section{Soundness test}

Soundness test is carried to find the expansion of cement paste at fresh state with the help of using le-chateliers apparatus. The test results showing the variation in expansion of cement paste when cement replaced with prosopis juliflora ash is shown in figure 2 . It is observed that with the increase in percentage of replacement of cement with prosopis juliflora ash expansion of cement paste reduces. This is mainly due to the presence of $\mathrm{MgO}$ in prosopis juliflora ash. The limit of acceptable soundness as per is 4031 is 10 $\mathrm{mm}$ and the tested results show that all the mixes were inside the acceptable range. 


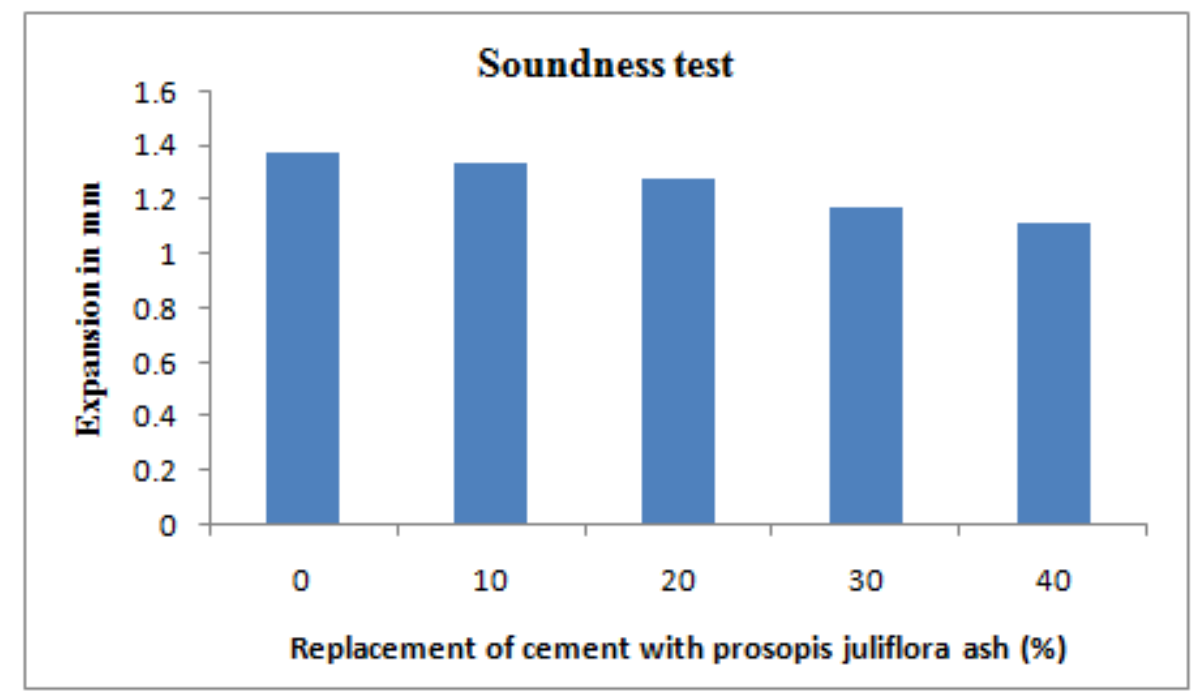

Fig. 2: Soundness Test

\section{Compressive strength}

The variation in the compressive strength results of the mortar mixes at 3, 7 and 28 days of curing with variation in the replacement level of cement with prosopis juliflora ash has been shown in Figure. 3. The compressive strength of the cement mortar mix at the age of 3 days curing was observed to be $49 \%$ of its 28 days compressive strength and that of 7 days curing was observed to be $72 \%$ of its 28 days compressive strength. For the mixes with $10 \%$ replacement level of cement with PJA, there was a slight increase in the compressive strength of $6 \%$ compared with the control mix, whereas at $20 \%$ replacement level, it was observed a slight reduction in the compressive strength of $1 \%$ with respect to the control mix. For $30 \%$ and $40 \%$ replacement level, the strength reduction was observed to be $18 \%$ and $29 \%$ respectively with respect to the control mix.

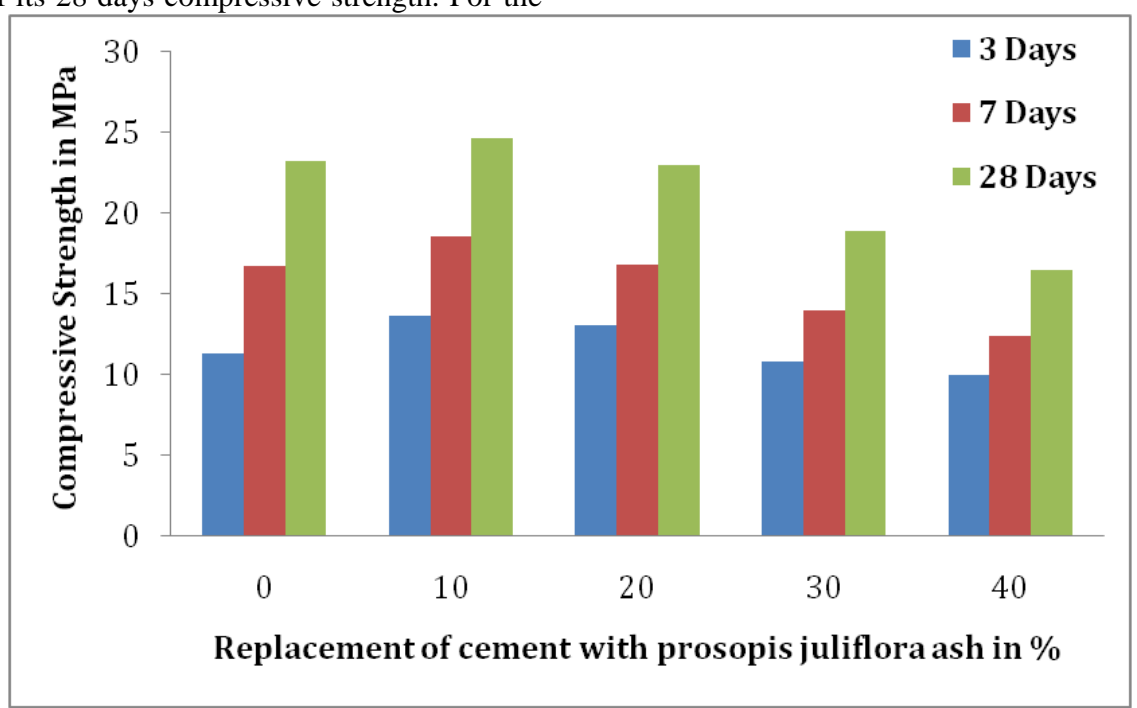

Fig. 3: Compressive Strength of Mortar

\section{Conclusion}

- The optimum water content required for standard consistency of cement paste is $35 \%$ upto $20 \%$ of replacement of prosopis juliflora ash after $20 \%$ the required amount of water increases to $37.5 \%$.

- With the increase in replacement of prosopis juliflora ash as cement, the initial setting time of cement paste also increases.

- The expansion of cement reduced with the increase in percentage of replacement of prosopis juliflora ash as cement.

- Upto $10 \%$ of replacement of cement by prosopis juliflora ash, the compressive strength of cement mortar increases to $6 \%$. Beyond $10 \%$ the strength decreases with the increase in replacement. For 30 and $40 \%$ of replacement strength decreases by $18 \%$ and $29 \%$ respectively.

\section{References}

[1] Shehdeh Ghannama, HusamNajmb,Rosa Vasconez 2015. Experimental study of concrete made with granite and iron powders as partial replacement of sand. Sustainable Materials and Technologies 9 1-9.

[2] Gurpreet Singh , Rafat Siddique Ph.D. 2016. Effect of iron slag as partial replacement of fine aggregates on the durability characteristics of self-compacting concrete. Construction and Building Materials $\underline{128} 88-95$.

[3] Ambedkar. B, Josephin Alex, Dhanalakshmi .J 2017. Enhancement of mechanical properties and durability of the cement concrete by RHA as cement replacement: Experiments and modeling. Construction and Building Materials 148 167-175.

[4] Jihwan Kim, Chongku Yi, Goangseup Zi 2015 Waste glass sludge as a partial cement replacement in mortar. Construction and Building Materials 75 242-246.

[5] Javad Torkaman, Alireza Ashori, Ali Sadr Momtazi 2014. Using wood fiber waste, rice husk ash, and limestone powder waste as 
cement replacement materials for lightweight concrete blocks. Construction and Building Materials $\underline{50}$ 432-436.

[6] Khalifa S. Al-Jabri , Makoto Hisada , Salem K. Al-Oraimi Abdullah H. Al-Saidy 2009. Copper slag as sand replacement for high performance concrete. Cement \& Concrete Composites 31 483-488.

[7] Felipe Rivera , Patricia Martínez , Javier Castro , Mauricio Lopez 2015. "Massive volume fly-ash concrete: A more sustainable material with fly $f$ bash replacing cement and aggregates". Cement and Concrete Composites 63 104-112

[8] Augustine Uche Elinwa, Yakubu Abba Mahmood 2002. Ash from timber waste as cement replacement material. Cement \& Concrete Composites 24 219-222.

[9] Soheil Oruji, Nicholas A. Brake, Likhith Nalluri, Ramesh K Guduru 2017. Strength activity and microstructure of blended ultrafine coal bottom ash-cement mortar. Construction and Building Materials 153 317-326.

[10] Manpreet Singh, Anshuman Srivastava, Dipendu Bhunia 2017. An investigation on effect of partial replacement of cement by waste marble slurry. Construction and Building Materials 134, 471-488. 